Otorhinolaryngological findings and hearing in HIV-positive and HIV-negative children in a developing country

\title{
Taipale, Anni
}

2011

Taipale , A , Pelkonen , T, Taipale , M , Roine , I , Bernardino , L , Peltola , H \& Pitkäranta , A 2011 , ' Otorhinolaryngological findings and hearing in HIV-positive and HIV-negative children in a developing country ' , European Archives of Oto-Rhino-Laryngology , vol. 268 , no. 10 , pp. 1527-1532 . https://doi.org/10.1007/s00405-011-1579-x

http://hdl.handle.net/10138/299298

https://doi.org/10.1007/s00405-011-1579-x

publishedVersion

Downloaded from Helda, University of Helsinki institutional repository.

This is an electronic reprint of the original article.

This reprint may differ from the original in pagination and typographic detail.

Please cite the original version. 


\title{
Otorhinolaryngological findings and hearing in HIV-positive and HIV-negative children in a developing country
}

\author{
Anni Taipale $\cdot$ Tuula Pelkonen $\cdot$ Marko Taipale • \\ Irmeli Roine $\cdot$ Luis Bernardino $\cdot$ Heikki Peltola \\ Anne Pitkäranta
}

Received: 5 November 2010/Accepted: 23 February 2011/Published online: 25 March 2011

(C) Springer-Verlag 2011

\begin{abstract}
The otorhinolaryngological (ORL) manifestations of Human Immunodeficiency virus (HIV) are common, but remain poorly characterized among children of Sub-Saharan Africa, where $90 \%$ of new pediatric infections occur. Our objective was to compare ORL findings and hearing in HIV-positive and -negative children of Luanda, Angola, using a comparative study of 78 outpatients from the HIV polyclinic and of 78 age- and sex-matched controls in a pediatric hospital with interview, general and ORL examination, brainstem auditory evoked potentials, and at age $>5$ years pure tone open-air audiometry. ORL pathology emerged in $92 \%$ of HIV-positive and $78 \%(p=0.02)$ of control children. HIV-associated ORL findings comprised dental caries (56 vs. $32 \% ; p=0.0009$ ), cervical lymphadenopathy $>1 \mathrm{~cm}$ (45 vs. $10 \% ; p<0.0001)$, facial skin lesions ( 32 vs. $5.1 \% ; p<0.0001$ ), chronic suppurative otitis media (26 vs. $3.8 \% ; p=0.0002$ ), dry tympanic membrane perforations ( 9 vs. $1 \% ; p=0.03$ ), tonsils of Mallampati score $0-1$ ( 87 vs. $64 \% ; p=0.0009$ ), and bilateral hearing
\end{abstract}

A. Taipale $(\bowtie) \cdot$ T. Pelkonen $\cdot$ H. Peltola $\cdot$ A. Pitkäranta Medical Faculty, Helsinki University, Helsinki, Finland e-mail: anni.taipale@fimnet.fi

A. Taipale · A. Pitkäranta

Department of Otorhinolaryngology, Helsinki University Central Hospital, Helsinki, Finland

A. Taipale $\cdot$ T. Pelkonen - M. Taipale $\cdot$ L. Bernardino Hospital Pediátrico David Bernardino, Luanda, Angola

T. Pelkonen $\cdot$ M. Taipale $\cdot$ H. Peltola

Hospital for Children and Adolescents, Helsinki University

Central Hospital, Helsinki, Finland

I. Roine

Universidad Diego Portales, Santiago, Chile loss of $>25 \mathrm{~dB}$ (13 vs. $1 \%$; $p=0.009)$. Other HIV-associated characteristics included ear pain (44 vs. 27\%; $p=0.006$ ), earlier otorrhea episodes (34 vs. 17\%; $p=0.004)$, tuberculosis (29 vs. $2.6 \% ; p<0.0001)$, and pneumonia (22 vs. $2.6 \% ; p=0.0003$ ). ORL pathology appeared usual in both HIV-positive and -negative children. However, the overall high frequency and severity of the findings among the HIV-positive children require regular inclusion of the ORL area in these children's clinical evaluation.

Keywords Children - Developing country · HIV . Otorhinolaryngology

\section{Introduction}

The otorhinolaryngological (ORL) manifestations of the human immunodeficiency virus (HIV) are various and emerge during disease progression in the vast majority of infected children [1-3]. Transmitted through body fluids and secretions and infecting specific subsets of leukocytes, HIV leads to progressive deterioration of the host's cellmediated immune system, and leads to lymphoid changes and opportunistic infections; these are often encountered in the head and neck area.

The profile of ORL findings among pediatric HIV patients is especially characterized by chronic or recurrent otitis media and enlargement of cervical lymph nodes $[1,3$, 4]. In addition, HIV involvement of the intraparotid and pharyngeal lymphoid tissue may lead to marked hypertrophy of these structures [5-7], whereas in the orofacial region, widespread lesions of viral and fungal infections, as well as dental caries, may occur [1, 3, 8]. HIV-infected children may also suffer from hearing loss of either 
peripheral or central origin $[9,10]$. However, several of these findings may frequently emerge among HIV-negative children as well, particularly in developing countries, where ORL illnesses are common.

Worldwide, there are more than two million HIV-positive children, and over $90 \%$ of new infections occur in SubSaharan Africa [11]. In Angola, a southwestern African country with a relatively low but constantly growing HIV rate (2.1\% of the adult population), the number of pediatric HIV patients is steadily increasing, reaching 17,000 in 2007 [12]. In developing countries, improved access to antiretroviral (ARV) therapy has raised the life-expectancy of HIV patients, emphasizing the role of recognition and treatment of even less severe manifestations of the disease, such as those concerning the ORL area.

This study was conducted to define and compare the ORL findings and hearing in HIV-positive and -negative children in Luanda, the capital of Angola.

\section{Children and methods}

Seventy-eight children attending an HIV consultation at the Pediatric Hospital (Hospital Pediátrico) of Luanda, Angola, and 78 age- and sex-matched outpatients (controls) from the surgical and general pediatric polyclinics of the hospital participated in the study during January-July 2008. The hospital's ethics committee accepted the study protocol, and an informed consent was obtained from the children's guardians.

All children underwent a structured interview, physical examination, ORL status including pneumatic otoscopy, and hearing screening. Any abnormal finding in the ORL status, including caries, was categorized as "ORL pathology". Children presenting at least one tooth with a decayed surface were diagnosed as having caries. HIV was diagnosed at the hospital's HIV polyclinic by a specific antibody-detecting test (Hexagon HIV ${ }^{\circledR}$ Human, Wiesbaden, Germany), and children with signs or symptoms indicative of WHO clinical disease stage 3 or 4 [13] were defined as having advanced disease. Children with weight-for-age $<-$ $2 \mathrm{SD}$ of the mean were regarded as malnourished. In diagnosis of pneumonia, chest X-ray was available in two cases; otherwise, diagnosis was based on a combination of cough, fever, tachypnea, and crepitation in auscultation. Tonsil size was classified according to the Mallampati score $(0$, tonsils fit within the tonsillar fossa; $1+$, tonsils $<25 \%$ of space between pillars; $2+$, tonsils $25-50 \%$ of space between pillars; $3+$, tonsils $50-75 \%$ of space between pillars; $4+$, tonsils $>75 \%$ of space between pillars).

The child was diagnosed as having acute otitis media (AOM) if he or she manifested in otoscopy a red or opaque tympanum without mobility, combined with at least one of the following symptoms: ear pain, fever, rhinorrhea, cough. In cases of otorrhea, chronic suppurative otitis media (CSOM) was diagnosed if the child's ear discharge had persisted for at least 2 weeks; otherwise, the case was defined as AOM. An ear-discharge smear was obtained with a sterile cotton swab from the external ear canal of 17 HIV-positive and one control child with CSOM. The samples were Gram-stained, cultured under aerobic conditions, and analyzed following the norms of the National Committee for Clinical Laboratory Standards.

The brainstem auditory evoked potentials, measured at 40, 60, and $80 \mathrm{~dB}$ (Bera MADSEN Octavus ${ }^{\circledR}$ system v. 2.001, Windows XP/2000 compatible; GN Otometrics, Denmark), were considered normal when showing a response at $40 \mathrm{~dB}$. Moderate hearing loss was diagnosed with a response threshold at $60 \mathrm{~dB}$, severe hearing loss at $80 \mathrm{~dB}$, and profound hearing loss when the response was lacking. Additionally, pure-tone air-conduction audiometry (Midimate 622 Clinical/Diagnostic Audiometer; Madsen Electronics, Denmark), screening at frequencies of 125 , 250, 500, 1,000, 2,000, 4,000, and $8,000 \mathrm{~Hz}$ without masking tone, was performed for children over 5 years. The average hearing threshold at $500-4,000 \mathrm{~Hz}$ was counted and scaled according to WHO standards: $\leq 25 \mathrm{~dB}$ for normal hearing and $26-40 \mathrm{~dB}$ for slight, $41-60 \mathrm{~dB}$ for moderate, $61-80 \mathrm{~dB}$ for severe, and at least $81 \mathrm{~dB}$ for profound hearing loss.

In data analysis, performed with Statview ${ }^{\circledR}$ program (v. 5.0.1, SAS Institute Inc., USA), p-values were calculated with Chi square, Fisher's exact test, and Mann-Whitney $U$ test. $p$ values $<0.05$ were considered statistically significant.

\section{Results}

Table 1 shows the demographic data of HIV-positive and control children. Thirty-six (46\%) HIV-infected children were on ARV treatment, and 41 (53\%) had advanced disease. Twenty-four (59\%) of the children with advanced disease were on ARV medication. Compared with control children, HIV children had more often received complete vaccinations $(p=0.02)$ and suffered from tuberculosis $(p<0.0001)$ and otorrhea episodes $(p=0.004)$. HIV-positive children also more often presented with ear pain $(p=0.006)$, enlarged liver $(p=0.007)$, pneumonia $(p=0.0003)$, and current treatment with antibiotics $(p<0.0001)$.

ORL pathology was detected in $72(92 \%)$ HIV-positive and $61(78 \% ; p=0.02)$ control children. The ORL findings associated with HIV comprised dental caries $(p=$ $0.0009)$, cervical lymphadenopathy $>1 \mathrm{~cm}(p<0.0001)$, facial skin lesions (folliculitis, molluscum contagiosum, 
Table 1 Characteristics of 78 HIV-positive and 78 control children in Luanda
$* p<0.05$

$* * p<0.01$

$* * * p<0.001$

${ }^{\text {a }}$ For at least several hours daily through public network

\begin{tabular}{lllc}
\hline & HIV children $(\%)$ & Controls $(\%)$ & $p$ value \\
\hline Median age in months (range) & $51(9-178)$ & $49.5(9-164)$ & \\
Female & $42(54)$ & $42(54)$ & \\
Median number of people in household & 5 & 6 & 0.81 \\
Malnourishment & $21(27)$ & $12 / 77(16)$ & 0.08 \\
Running water at home & $24 / 77(31)$ & $28(36)$ & 0.53 \\
Electricity & $61 / 77(79)$ & $61(78)$ & 0.88 \\
Attending a vaccination program & $70 / 76(92)$ & $61(78)$ & $0.02^{*}$ \\
Malaria, earlier & $72(92)$ & $73(94)$ & $>0.99$ \\
Typhoid fever, earlier & $18(23)$ & $21(27)$ & 0.61 \\
Tuberculosis, now or earlier & $22 / 77(29)$ & $2 / 77(3)$ & $<0.0001^{* * *}$ \\
Pneumonia & $17(22)$ & $2(3)$ & $0.0003^{* * *}$ \\
Diarrhea & $2(3)$ & $5 / 77(6)$ & 0.44 \\
Enlarged liver & $8(10)$ & 0 & $0.007^{* *}$ \\
Enlarged spleen & $3(4)$ & 0 & 0.25 \\
Cardiac murmur & $8(10)$ & $2(3)$ & 0.10 \\
Developmental delay & $3(4)$ & $1(1)$ & 0.62 \\
Antibiotics at time of examination & $61(78)$ & $13(17)$ & $<0.0001^{* * *}$ \\
Otorrhea, now or earlier & $34(44)$ & $17(22)$ & $0.004^{* *}$ \\
\hline
\end{tabular}

eczema; $p<0.0001)$, CSOM ( $p<0.0001)$, nondischarging tympanic membrane perforations $(p=0.03)$, and small tonsils ( $p=0.0009$ ) (Table 2$)$. In addition, the following conditions were detected among HIV-positive subjects (one case of each): gingivitis, sinusitis, oral petecchiae, facial lipoatrophy, and cervical abscess $(9 \mathrm{~cm}$ in diameter; surgically drained). One HIV-positive boy had a cystic, clear-blue tumor of $1.5 \mathrm{~cm}$ on the bottom of the oral cavity, together with an adjacent $3 \mathrm{~cm}$ submandibular lymph node; histological diagnosis of the tumor was unavailable. Three children's uvulas had been removed as a traditional treatment for cough.

The prevalence of caries in HIV-positive children varied according to age, being $9 \%$ in children $<2$ years, $30 \%$ in $2-$ to 3 -year-olds, $50 \%$ in 3- to 4-year-olds, $91 \%$ in 4 - to 5 -year-olds, and $71 \%$ in children $\geq 5$ years. The corresponding figures among control children were $0,17,17,57$, and $56 \%$. HIV-related enlarged lymph nodes were most
Table 2

Otorhinolaryngological findings in $78 \mathrm{HIV}$-positive and 78 control children in Luanda
$* p<0.05$

$* * p<0.01$

$* * * p<0.001$

${ }^{a}$ Mallampati score: tonsils at least $25 \%$ of the space between pillars

\begin{tabular}{lllc}
\hline & HIV children $(\%)$ & Controls $(\%)$ & $p$ value \\
\hline $\begin{array}{l}\text { Skin lesions (eczema, molluscum contagiosum, } \\
\text { folliculitis) }\end{array}$ & $25(32)$ & $4(5)$ & $<0.0001^{* * *}$ \\
Rhinorrhea & $30(38)$ & $29(37)$ & $>0.99$ \\
Angular cheilitis & $2(3)$ & 0 & 0.50 \\
Oral ulcerations & $4(5)$ & 0 & 0.12 \\
Dental caries & $44(56)$ & $25(32)$ & $0.0009^{* * *}$ \\
Oral candidiasis & $9(12)$ & $5(6)$ & 0.40 \\
Tonsil size $\geq 2+{ }^{\text {a }}$ & $10(13)$ & $28(37)$ & $0.0009^{* * *}$ \\
Hoarseness & $5(6)$ & $3(6)$ & 0.72 \\
Parotid enlargement & $2(3)$ & 0 & 0.50 \\
Preauricular fistule & $2(3)$ & $2(3)$ & $>0.99$ \\
Cervical lymphadenopathy $>1 \mathrm{~cm}$ & $35(45)$ & $8(10)$ & $<0.0001^{* * * *}$ \\
Ear pain & $44(56)$ & $27(35)$ & $0.006^{* *}$ \\
Acute otitis media & $8(10)$ & $9(12)$ & $>0.99$ \\
Chronic suppurative otitis media & $21(27)$ & $3(4)$ & $<0.0001^{* * *}$ \\
Dry tympanic perforation & $7(9)$ & $1(1)$ & $0.03^{*}$ \\
Cerumen-impacted auditory canal & $26(33)$ & $34(44)$ & 0.25 \\
Any otorhinolaryngological pathology & $72(92 \%)$ & $61(78 \%)$ & $0.02^{*}$ \\
\hline
\end{tabular}


frequently located in the upper jugular (66\%), submandibular/submental $(37 \%)$, and posterior cervical $(31 \%)$ zones.

Among the HIV children, the prevalence of CSOM appeared highest $(5 / 14 ; 36 \%)$ in children aged $0-2$ years. The disease was bilateral in $8 / 21$ HIV-positive children $(38 \%)$, whereas all three cases in control children were unilateral. Proteus vulgaris $(9 / 17 ; 53 \%)$ and Pseudomonas aeruginosa $(4 / 17 ; 24 \%)$ proved the major causative agents among the HIV children, and the one ear-discharge smear obtained from a control child yielded $P$. aeruginosa.

Apart from otitis media and dry perforations (Table 2), the HIV children exhibited a normal tympanum in 74/156 ears $(47 \%)$, cerumen blockage in $32 / 156$ ears $(21 \%)$, and tympanic retraction in $3 / 156$ ears $(2 \%)$. Control children displayed a normal tympanum in 96/156 ears (62\%), cerumen blockage in $41 / 156$ ears (26\%), and tympanic scarring in $1 / 156$ ears $(1 \%)$.

In the hearing evaluation (Table 3), 20 HIV-positive children (26\%) aged 15-140 months (median 65 months) showed hearing loss: 10 cases (13\%) were bilateral, of which $5(6 \%)$ at least a moderate degree. Of the control children, $12(15 \%)$ presented with elevated hearing thresholds and one case (1\%) appeared bilateral. The background for HIV children's hearing loss comprised CSOM (12/30 ears; 40\%), cerumen blockage (7/30; 23\%), dry tympanic perforation $(5 / 30 ; 17 \%)$, undetermined $(4 / 30$; $13 \%)$, and tympanic retraction $(2 / 30 ; 7 \%)$. In the control group, hearing loss was related to cerumen blockage $(5 / 13$ ears; $38 \%)$, undetermined factors $(5 / 13 ; 38 \%)$, AOM (2/13; $15 \%)$, and CSOM $(1 / 13 ; 8 \%)$. Compared with the control group, HIV-positive children were significantly more likely to present with bilateral hearing impairment $(p=0.009)$.
Overall, the differences in status findings between the ARV- and non-ARV-treated HIV-positive children were not significant.

\section{Discussion}

Pathological ORL findings were very common in both HIV-positive (92\%) and HIV-negative (78\%) children. However, the profiles of typical ORL findings in these two groups differed markedly. The HIV-associated ORL findings comprised cervical lymphadenopathy, dermal lesions, chronic otitis, small tonsils, dental caries, and hearing loss.

Although HIV positivity in children is increasing in developing countries, only a few reports, including one small prospective and comparative study, exist on ORL findings in these children (Table 4) [2, 3, 14, 15].

The most usual HIV-associated ORL manifestation in our study was cervical lymphadenopathy $>1 \mathrm{~cm}$, occurring in nearly half of the HIV-positive children. This was not surprising, as HIV-positive children are commonly known to present with lymph node enlargement, especially in the head and neck area, even if they are otherwise asymptomatic $[3,13,16]$. However, $10 \%$ of the control children also showed cervical lymph node swelling, making this alone an unreliable sign of HIV positivity.

One-third of the HIV-positive children carried extensive skin lesions, such as eczema and molluscum contagiosum, which are the commonly known manifestations in HIVpositive children and denote clinical disease stage 2 (mildly symptomatic) [13]. The lack of skin problems in control children further emphasizes the significance of skin lesions as indicators of HIV positivity.
Table 3 Hearing thresholds of 78 HIV-positive and 78 control children in Luanda a Average hearing threshold of $500,1,000,2,000$, and $4,000 \mathrm{~Hz}$; performed on children aged over 5 years

\begin{tabular}{|c|c|c|c|c|}
\hline & \multicolumn{2}{|l|}{ HIV group } & \multicolumn{2}{|l|}{ Control group } \\
\hline & $\begin{array}{l}\text { All ears } \\
N=156(\%)\end{array}$ & $\begin{array}{l}\text { Better-hearing } \\
\text { ears } N=78(\%)\end{array}$ & $\begin{array}{l}\text { All ears } \\
N=156(\%)\end{array}$ & $\begin{array}{l}\text { Better-hearing } \\
\text { ears } N=78(\%)\end{array}$ \\
\hline \multicolumn{5}{|c|}{ Brainstem auditory evoked potentials } \\
\hline $40 \mathrm{~dB}$ & $142(91)$ & $75(96)$ & $145(93)$ & $75(96)$ \\
\hline $60 \mathrm{~dB}$ & $8(5)$ & $1(1)$ & $4(3)$ & \\
\hline $80 \mathrm{~dB}$ & $4(3)$ & $2(3)$ & & \\
\hline No response & $2(1)$ & & & \\
\hline Failed & & & $7(4)$ & $3(4)$ \\
\hline \multicolumn{5}{|c|}{ Pure-tone audiometry ${ }^{\mathrm{a}}$} \\
\hline$\leq 25 \mathrm{~dB}$ & $39 / 58(67)$ & $22 / 29(76)$ & $53 / 62(85)$ & $30 / 31(97)$ \\
\hline $26-40 \mathrm{~dB}$ & $11 / 58(19)$ & $5 / 29(17)$ & $10 / 62(15)$ & $1 / 31(3)$ \\
\hline $41-60 \mathrm{~dB}$ & $5 / 58(8)$ & $1 / 29(3)$ & & \\
\hline $61-80 \mathrm{~dB}$ & $2 / 58(3)$ & $1 / 29(3)$ & & \\
\hline$\geq 81 \mathrm{~dB}$ & & & & \\
\hline
\end{tabular}




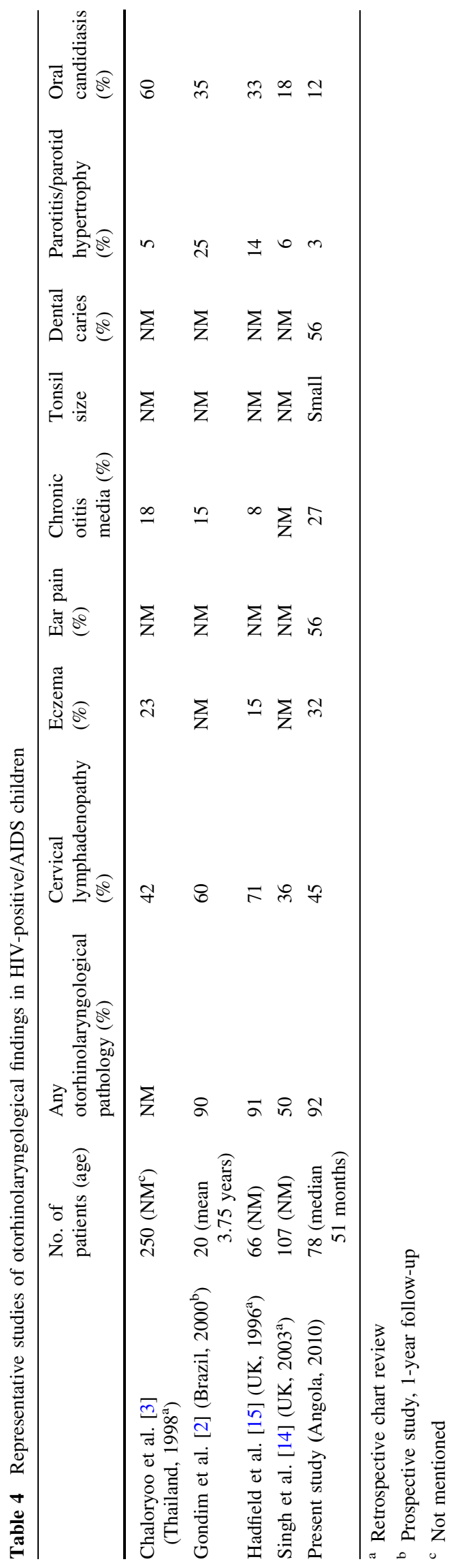

Chronic otorrhea affected one-quarter of the HIV children, especially those aged under 2 years. Previous studies from developed and developing countries confirm the association between HIV and chronic otitis [1-4, 14-18], CSOM being categorized as a mild symptom of HIV [13]. Even though our control children also exhibited a relatively high CSOM prevalence, the presence of chronic ear discharge, especially bilateral, appeared strongly suggestive of HIV positivity. In accordance with earlier studies, lower respiratory tract infections, such as tuberculosis and pneumonia, also appeared significantly more common in our HIV-positive children $[3,6]$.

HIV-positive children exhibited significantly smaller tonsils than control children. Previous studies on HIVpositive children have mainly detected hypertrophy of the adenotonsillar tissue [5, 15]; one study reported adenoidal atrophy [19]. However, a series from Spain showed the adenotonsillar tissue to initially enlarge, but to significantly diminish as the disease progressed [20]. In our study, clinical disease stage and tonsil size did not correlate. Nevertheless, our HIV children's generally small tonsil size, as well as the absence of marked adenotonsillar hypertrophy, may at least partially reflect their overall poor clinical condition. Of note, parotid enlargement was present in only $3 \%$ of the HIV children, which is equal to or less than in earlier studies [2, 3, 6, 14-16].

Dental caries appeared a serious problem in all of the children, particularly in the HIV-positive, whom it affected not only more frequently, but also at a younger age and with greater severity. Our result of $56 \%$ in the HIV group is consistent with the previous reports of $58 \%$ and $60 \%$ among pediatric HIV patients [8, 21]. Dental health, even though comprising an entity apart from the ORL field, markedly accounts for child's quality of life and should therefore be noted when examining the oral cavity.

One-quarter of the HIV-positive children suffered from hearing loss in one or both ears. Bilateral hearing impairment, associated with HIV positivity, was present in over $10 \%$. Our results are in accordance with previous studies from Brazil, describing unilateral or bilateral hearing loss in $23-37 \%$ of HIV-infected children [9, 10]. However, these figures refer to children with hearing thresholds above 15-20 dB, whereas our study applied less sensitive criteria $(>25 \mathrm{~dB})$ for hearing loss. Consistent with the aforementioned studies, the majority of our hearing impairment cases were related to middle-ear infections.

A common dilemma in developing countries, cerumen impaction [22], was also detected in our study in both groups of children. After excluding the cases with contralateral otitis or a history of ear pain, otorrhea, or ototoxic drugs, cerumen remained the only apparent etiologic factor for hearing loss in seven children. 


\section{Conclusion}

Our study showed ORL diseases to be significantly common in HIV-positive children. Routine evaluation of the ORL area and hearing in these heavily burdened children could substantially improve their quality of life.

Acknowledgments We thank all of the participating children and their guardians and the personnel of Hospital Pediátrico. David Bernardino and especially Elizabete Anjos and Marlene Pardal, who mostly performed the laboratory diagnostics in Luanda, are particularly thanked. We also gratefully acknowledge a research grant from the Väinö and Laina Kivi Foundation.

Conflict of interest The authors declare that they have no conflicts of interest.

\section{References}

1. Chow JH, Stern JC, Kaul A, Pincus RL, Gromisch DS (1990) Head and neck manifestations of the acquired immunodeficiency syndrome in children. Ear Nose Throat J 69(6):416-419, 422-423

2. Gondim LA, Zonta RF, Fortkamp E, Schmeling RO (2000) Otorhinolaryngological manifestations in children with human immunodeficiency virus infection. Int J Pediatr Otorhinolaryngol 54(2-3):97-102

3. Chaloryoo S, Chotpitayasunondh T, Chiengmai PN (1998) AIDS in ENT in children. Int J Pediatr Otorhinolaryngol 44(2):103-107

4. Williams MA (1987) Head and neck findings in pediatric acquired immune deficiency syndrome. Laryngoscope 97(6):713-716

5. Dargent JL, Lespagnard L, Kornreich A, Hermans P, Clumeck N, Verhest A (2000) HIV-associated multinucleated giant cells in lymphoid tissue of the Waldeyer's ring: a detailed study. Mod Pathol 13(12):1293-1299

6. Bagenda D, Nassali A, Kalyesubula I, Sherman B, Drotar D, Boivin MJ et al (2006) Health, neurologic, and cognitive status of HIV-infected, long-surviving, and antiretroviral-naive Ugandan children. Pediatrics 117(3):729-740

7. Dave SP, Pernas FG, Roy S (2007) The benign lymphoepithelial cyst and a classification system for lymphocytic parotid gland enlargement in the pediatric HIV population. Laryngoscope 117(1):106-113

8. Eldridge K, Gallagher JE (2000) Dental caries prevalence and dental health behaviour in HIV infected children. Int J Paediatr Dent 10(1):19-26
9. Matas CG, Leite RA, Magliaro FC, Goncalves IC (2006) Audiological and electrophysiological evaluation of children with acquired immunodeficiency syndrome (AIDS). Braz J Infect Dis 10(4):264-268

10. Palacios GC, Montalvo MS, Fraire MI, Leon E, Alvarez MT, Solorzano F (2008) Audiologic and vestibular findings in a sample of human immunodeficiency virus type-1-infected Mexican children under highly active antiretroviral therapy. Int $\mathbf{J}$ Pediatr Otorhinolaryngol 72(11):1671-1681

11. UNAIDS. AIDS epidemic update: November 2009. Geneva 2009; UNAIDS/09.36E/JC1700E

12. UNAIDS/WHO Working Group on Global HIV/AIDS and STI Surveillance. UNAIDS/WHO Epidemiological Fact Sheets on HIV and AIDS, 2008 Update. Geneva 2008

13. World Health Organization. WHO case definitions of HIV for surveillance and revised clinical staging and immunological classification of HIV-related disease in adults and children. Geneva 2007

14. Singh A, Georgalas C, Patel N, Papesch M (2003) ENT presentations in children with HIV infection. Clin Otolaryngol Allied Sci 28(3):240-243

15. Hadfield PJ, Birchall MA, Novelli V, Bailey CM (1996) The ENT manifestations of HIV infection in children. Clin Otolaryngol Allied Sci 21(1):30-36

16. Nkrumah FK, Choto RG, Emmanuel J, Kumar R (1990) Clinical presentation of symptomatic human immuno-deficiency virus in children. Cent Afr J Med 36(5):116-120

17. Chen AY, Ohlms LA, Stewart MG, Kline MW (1996) Otolaryngologic disease progression in children with human immunodeficiency virus infection. Arch Otolaryngol Head Neck Surg 122(12):1360-1363

18. Shapiro NL, Novelli V (1998) Otitis media in children with vertically-acquired HIV infection: the Great Ormond Street Hospital experience. Int J Pediatr Otorhinolaryngol 45(1):69-75

19. Balsam D, Kanth N, Balbi H (1995) Abnormally small adenoids in HIV-infected children. Pediatr Radiol 25(1):74-76

20. Benito MB, Sampelayo TH, Gurbindo D, Sanchez-Ramon BS, Gomez EM, Munoz-Fernandez MA (1999) Adenoidal tissue mass as a clinical guide of disease evolution in vertically HIV-1 infected children. Int J Pediatr Otorhinolaryngol 51(3):145-155

21. Massarente DB, Domaneschi C, Antunes JL (2009) Untreated dental caries in a Brazilian paediatric AIDS patient population. Oral Health Prev Dent 7(4):403-410

22. Olusanya BO, Okolo AA, Ijaduola GT (2000) The hearing profile of Nigerian school children. Int J Pediatr Otorhinolaryngol 55(3):173-179 